\title{
Performance of joints in reinforced concrete slabs for two-way spanning action
}

1 John Stehle PhD R\&D Engineer, Laing O'Rourke plc, Dartford, UK

2 Antonios Kanellopoulos PhD

Research Fellow, School of Engineering, University of Cyprus, Nicosia, Cyprus
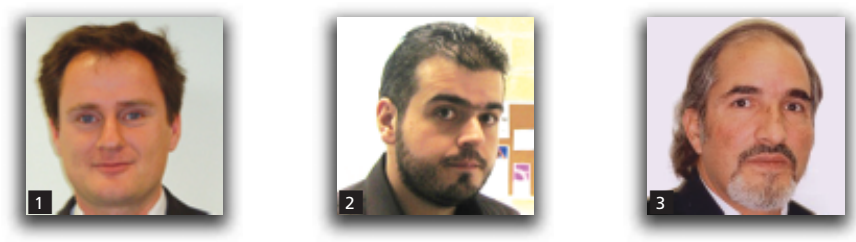

A series of tests on filigree slab joints was performed with the aim of assessing whether such joints can be reliably used in the construction of two-way spanning reinforced concrete slabs. The test results were compared with code requirements. Adequate joint performance is shown to be achievable when the joints are appropriately detailed. Further research is recommended for the formulation of a more generic understanding when the design parameters are varied from those studied in this work.

\section{Introduction}

Over the last decade the development and implementation of construction methods that result in more cost-effective, time saving and safer solutions than conventional methods have attracted much interest. One such method of construction being pursued involves the use of filigree flooring system arrangements (alternatively known as filigree slabs) for two-way spanning action, typically for grid sizes of the order of $8 \mathrm{~m}$ by $8 \mathrm{~m}$. Filigree slabs are also known in the UK as Omnia slabs, due to when the technology still remained under patent protection to a German inventor (Kanellopoulos et al., 2007). Filigree slabs comprise a precast concrete plank, typically $60 \mathrm{~mm}$ thick, containing a light reinforcement fabric, which provides strength for bending in the final condition, and a lattice girder truss that protrudes from the plank to provide spanning stiffness in the temporary state and horizontal shear strength to ensure composite action is achieved with the structural concrete topping that is poured on site (see Figure 1).

The number of filigree slabs that have been constructed in twoway spanning action is limited. However, there are a few known examples in the UK, including an office block at the Learning Resource Centre of Sheffield University and a $60000 \mathrm{~m}^{2}$ hospital building in Stoke-on-Trent (Figure 2). Slab designs that incorporate filigree principles are manufactured under various trade names (see Figures 1 and 3) but they really just vary in the geometry of the void formers if present.

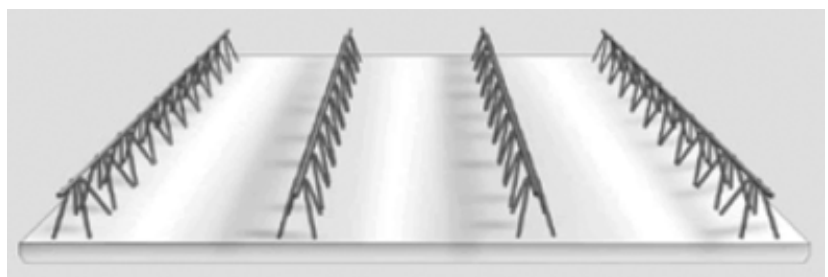

Figure 1. Typical filigree plank (HCP, 2010)

\section{Technical issues}

The application of filigree slabs for two-way spanning action can be justified with existing Eurocode and international standards. However, some estimates of shear friction strength - an important component of the load transfer mechanism - vary among the codes, and friction values are highly dependent on the construction process. A sequence of bending tests was thus conducted to improve understanding and raise confidence in the use of filigree slabs.

It is important to identify the fundamental differences between filigree slabs and in situ slabs. In situ members normally comprise a reinforcement fabric (or bars) in the top and bottom layers, cast on site within concrete. Filigree slabs (Figure 4) are almost the same as in situ slabs except 


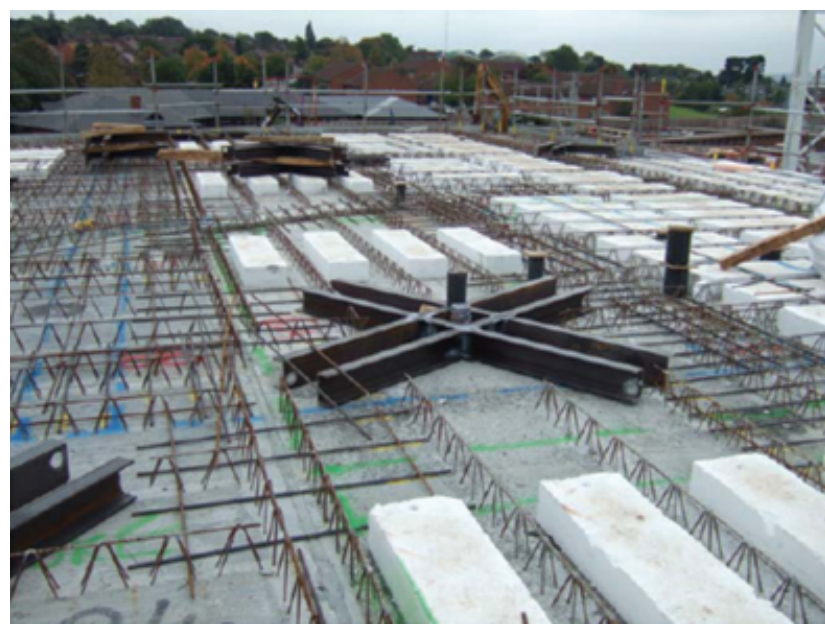

Figure 2. Two-way spanning filigree slab under construction by Laing O'Rourke plc at Stoke-on-Trent, UK, 2008

(a) there is a break in the bottom layer of concrete and fabric at the joints

(b) there is a horizontal construction joint between the precast plank and in situ concrete

(c) lattice girders are present, linking the precast and in situ concrete.

The main issues that need to be considered from a structural strength viewpoint are how the positive and negative bending moments may be transferred across the joints. For positive bending, the bottom fabric goes into tension, and thus at the joint in planks a loose 'lap' bar needs to be introduced to transfer the fabric forces to the adjacent plank. To achieve this, a number of load transfers need to be considered (Figure 5) (Cheng, 1995)

(a) from tension in bottom fabric to surrounding precast concrete - anchorage in precast

(b) from precast concrete to in situ concrete - horizontal shear

(c) from in situ concrete to tension in 'lap' bar - anchorage in in situ concrete

and on the other side of the joint (in reverse)

(d) from tension in 'lap' bar to in situ concrete - anchorage in in situ concrete

(e) from in situ concrete to precast concrete - horizontal shear

$(f)$ from precast concrete to tension in bottom fabric anchorage in precast.

Steps $(a)$ to $(c)$ and steps $(d)$ to $(f)$ may also be considered as offset 'laps'.

For negative bending, the situation is similar, except that compression forces need to be transferred across the joint; these

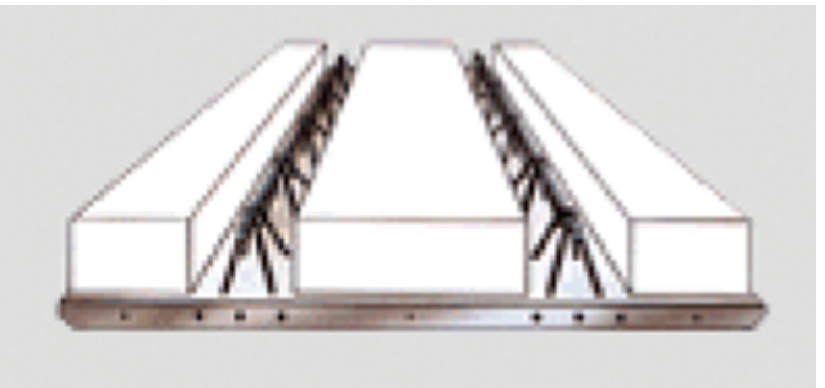

(a)

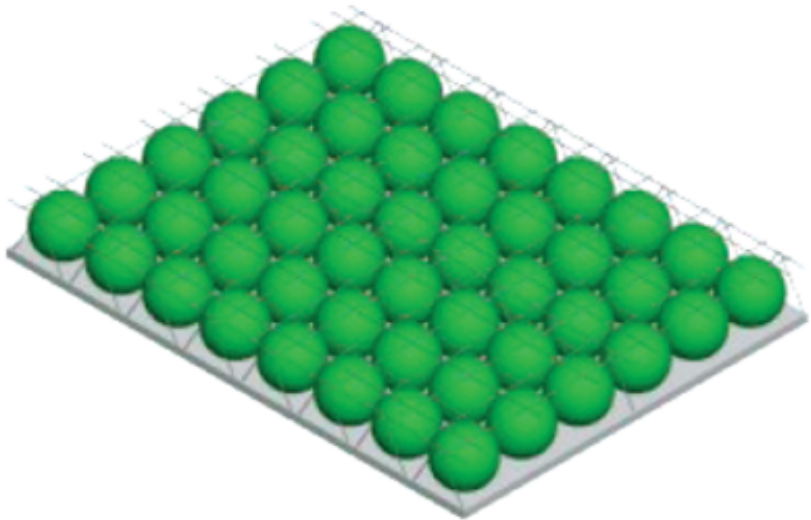

(b)

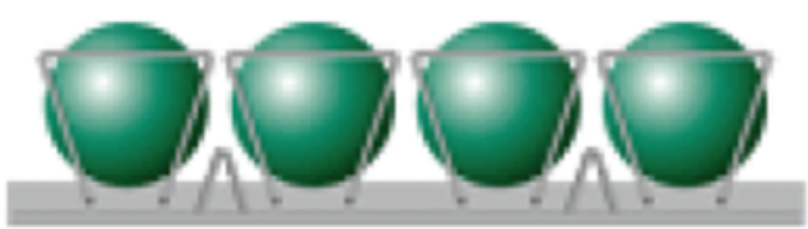

(c)

Figure 3. Filigree slab designs with: (a) Omnicore polystyrene void formers; (b) void formers (BubbleDeck, 2010); (c) void formers within lattice girder (Cobiax Technology, 2010)

compression forces begin in not only the fabric, but also the concrete below the neutral axis for bending. Hence, the load transfers that need to be considered are (Figure 6)

(g) from compression in bottom fabric and concrete below neutral axis to surrounding precast and in situ concrete anchorage in precast

(h) from precast concrete to in situ concrete - horizontal shear

(i) from in situ concrete to compression in 'lap' bar and in situ concrete - anchorage in in situ

and on the other side of the joint (in reverse)

( $j$ ) from compression in 'lap' bar and in situ concrete to in situ concrete - anchorage in in situ concrete

(k) from in situ concrete to precast concrete - horizontal shear 


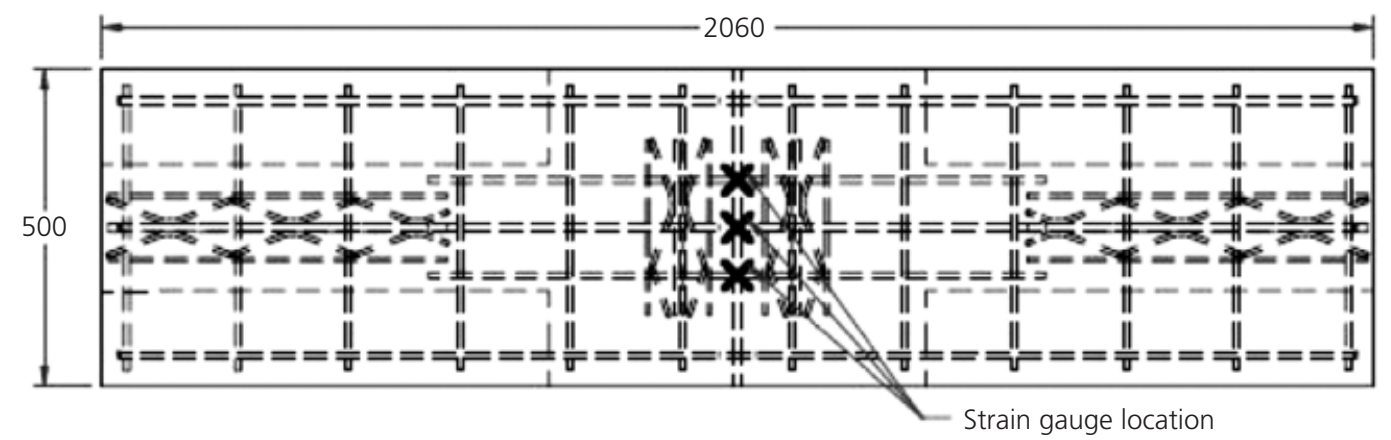

(a)

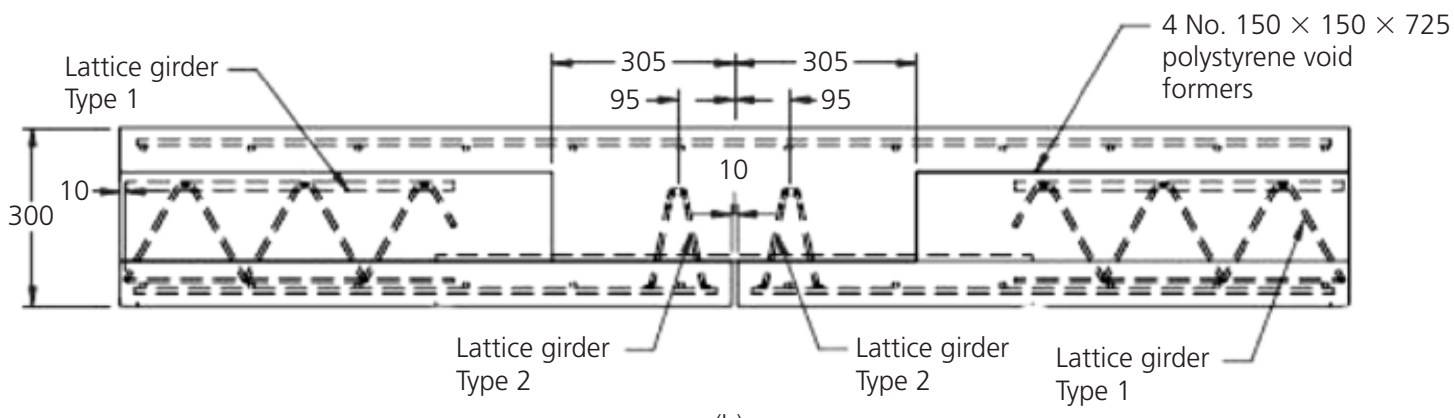

(b)

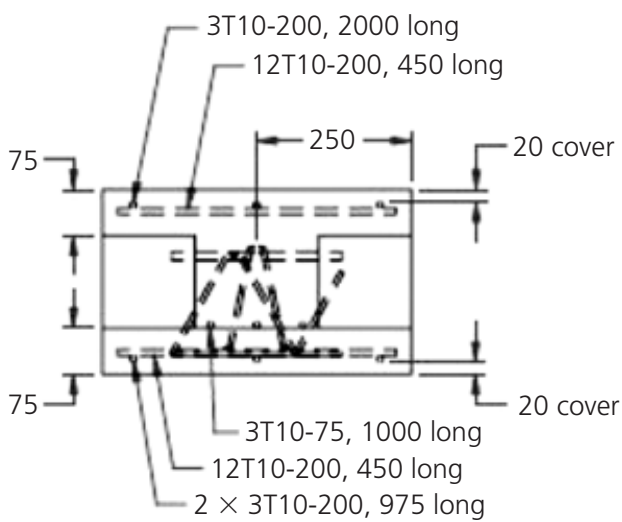

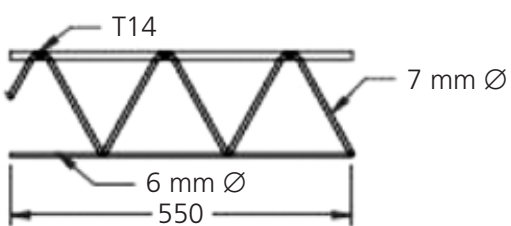

Lattice girder type 1

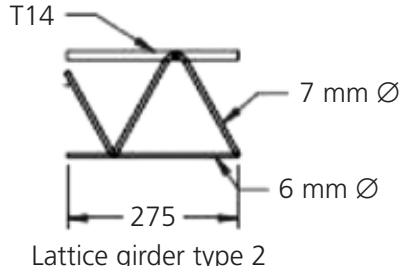

(c)

Lattice girder type 2

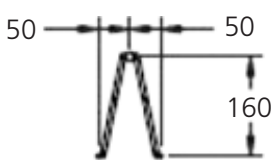

End elevation

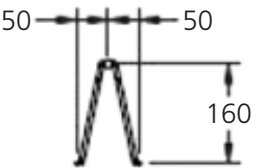

End elevation

Figure 4. Technical drawings of the filigree slabs: (a) plan; (b) front elevation; (c) side elevation and lattice girder detail (dimensions in millimetres)

(l) from precast and in situ concrete to compression in bottom fabric and concrete below neutral axis - anchorage in precast.

Again, steps $(g)$ to $(i)$ and steps $(j)$ to $(l)$ may also be considered as offset 'laps'.

The magnitude of the force transfers involved can be estimated by hand calculation using the relevant codes of practice.

\subsection{Anchorage of bars}

Clause 8.4.2(2) of BS EN 1992-1-1: 2004 (BSI, 2004) gives an ultimate anchorage bond stress according to:

1. $f_{\text {bd }}=2 \cdot 25 \eta_{1} \eta_{2} f_{\text {ctd }}$

where $\eta_{1}$ is a factor depending on the quality of bond $(=1.0$ for good bond conditions), $\eta_{2}$ is a factor depending on bar diameter 


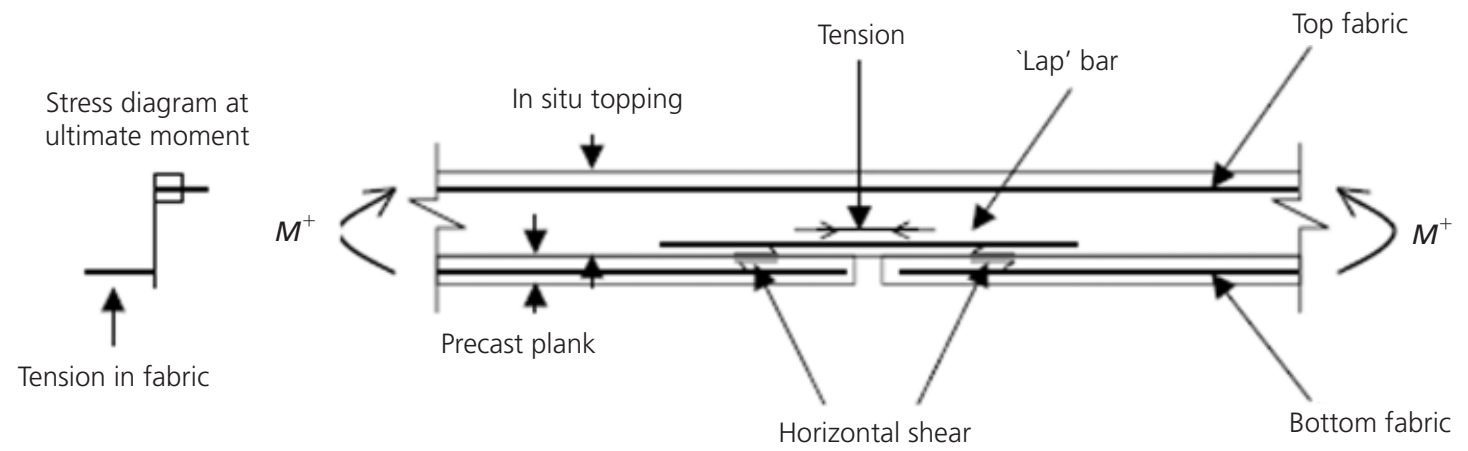

Figure 5. Flow of forces for positive bending moment

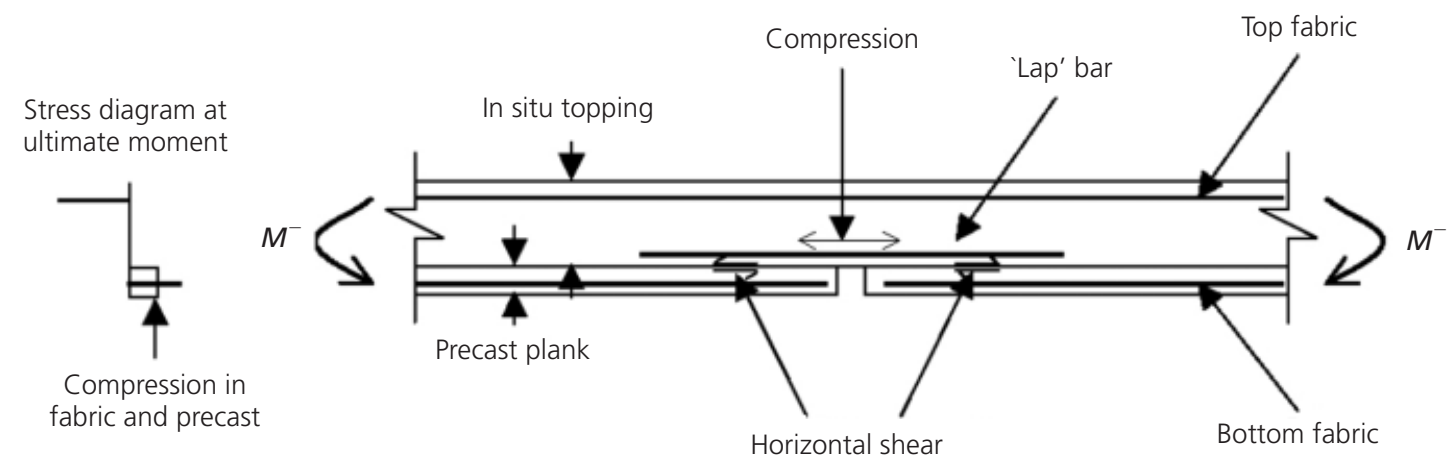

Figure 6. Flow of forces for negative bending moment

(=1.0 for bars less than $32 \mathrm{~mm}$ diameter) and $f_{\text {ctd }}$ is the design value of the concrete tensile strength. The bond stress is assumed to be constant over the anchorage length according to Clause 8.4.3(2) of BS EN 1992-1-1: 2004.

Based on these assumptions, for a grade $500,10 \mathrm{~mm}$ diameter bar embedded in grade C37 (cube strength) concrete, a maximum design anchorage length of $362 \mathrm{~mm}$ is calculated. Considering that a 'lap' bar may sit directly on a precast plank, there may not be full bond around the circumference of the bar.

Table 8.2 of BS EN 1992-1-1: 2004 provides a multiplier to account for the effect of cover according to Equation 2. Ignoring the upper bound limit, as it is not clear that the code intended to address a situation of zero cover, a cover of $0 \mathrm{~mm}$ and a $10 \mathrm{~mm}$ bar diameter results in $\alpha_{2}=1 \cdot 15$ :

2.

$$
\alpha_{2}=1-0 \cdot 15 \frac{\mathrm{c}_{\mathrm{d}}-\phi}{\phi}
$$

where $c_{\mathrm{d}}$ is the cover, $\phi$ is the bar diameter and $\alpha_{2} \geqslant 0 \cdot 7, \quad \alpha_{2} \leqslant 1 \cdot 0$.

For greater conservatism, pending further research, it is proposed that only $75 \%$ of the circumference be assumed to provide effective bond, so that a required design anchorage length of $483 \mathrm{~mm}$ is anticipated.

\subsection{Horizontal shear between precast and in situ concrete}

Clause 6.2.5(1) of Eurocode BS EN 1992-1-1: 2004 (BSI, 2004) defines the design shear strength of a horizontal interface according to Equation 3 (perpendicular stress term omitted):

$$
v_{\mathrm{Rdi}}=c f_{\mathrm{ctd}}
$$

3

$$
+\rho f_{\mathrm{yd}}(\mu \sin \alpha+\cos \alpha) \leqslant 0 \cdot 5 v f_{\mathrm{cd}}
$$

where $c=0.45$ and $\mu=0.7$ for a roughened surface, $\alpha$ is the inclination of reinforcement to the shear plane, $f_{\mathrm{yd}}$ is the design yield strength, $f_{\mathrm{cd}}$ is the design compressive strength and

$$
v=0 \cdot 6\left(1-\frac{f_{\mathrm{ck}}}{250}\right)
$$

where $f_{\text {ck }}$ is the characteristic compressive strength.

Using Equation 3, for grade 500, four anchored $7 \mathrm{~mm}$ diameter link bars at $73^{\circ}$, as per test 3 (Figure 4c), taking the contact area 
equal to $500 \mathrm{~mm}$ wide (specimen width) by $500 \mathrm{~mm}$ long (length of bar lap), then $v_{\mathrm{Rdi}}=154 \mathrm{kN}$. The maximum force that would be applied under ultimate loading is the yield strength of the three $10 \mathrm{~mm}$ diameter grade 500 'lap' bars, which is $117.8 \mathrm{kN}$. Since $154>117 \cdot 8$, the horizontal shear strength may be deemed satisfactory.

Clause 11.6.4 of ACI 318-08 (ACI, 2008) also provides guidance on the issue of shear strength provided at an interface by intersecting reinforcement. Where a bar is inclined at an angle $\alpha_{\mathrm{f}}$ to the shear plane, the shear strength is calculated according to (clause 11.6.4.2 of ACI 318-08):

\section{4. $\quad V_{\mathrm{n}}=A_{\mathrm{vf}} f_{\mathrm{y}}\left(\mu \sin \alpha_{\mathrm{f}}+\cos \alpha_{\mathrm{f}}\right)$}

where $\mu=0.6$ in accordance with clause 11.6.4.3 of ACI 318-08, $A_{\mathrm{vf}}$ is the area of shear friction and $f_{\mathrm{y}}$ is the yield strength of steel.

Using Equation 4, for grade 500 and four anchored $7 \mathrm{~mm}$ diameter link bars, as per test 3 (Figure 4) with bars inclined at $73^{\circ}$, a shear strength of $67 \mathrm{kN}$ is calculated. This is less than the apparent yield strength of the lap bars of $117 \cdot 8 \mathrm{kN}$, and less than the value predicted by the Eurocode approach. So, the ACI method appears to be more conservative than the Eurocode approach. However, it is noted that the commentary in ACI 318 08 acknowledges that higher shear strength may be possible, with a higher shear friction value of $\mu=0.8$ and a concrete shear strength term allowable, which aligns better with the Eurocode recommendations.

\subsection{Offset laps}

Clause 8.7.2(3) of BS EN 1992-1-1: 2004 provides guidance that the lap length should be increased by the amount of offset if the offset is greater than $50 \mathrm{~mm}$ or four bar diameters. This is the case in Figure 4, where the clear offset is $45 \mathrm{~mm}$ (i.e. greater than four bar diameters $=40 \mathrm{~mm}$ ). Hence, the lap length of $483 \mathrm{~mm}$ discussed earlier should be increased by $45 \mathrm{~mm}$, giving a required lap length of $528 \mathrm{~mm}$. Note that a lap length of $500 \mathrm{~mm}$ was provided in the testing, as explained in the following sections.

\section{Experimental set-up}

A series of test specimens representing joints in filigree slabs containing polystyrene void formers (similar to those shown in Figure 3(a)) was conducted. The general construction details of the test specimens are given in Figure 4. The purpose of the tests was to study the behaviour of the composite flooring systems in both positive and negative bending. For that reason, five composite slabs were prepared incorporating typical $35 \mathrm{MPa}$ (28-day cube strength) fresh concrete and precast concrete planks. Two monolithic specimens were also made using solely fresh concrete. These specimens functioned as the control. Table 1 summarises the test specimens and loading details.

Figure 7 shows the test set-up. The test was carried out in fourpoint bending in a stiff self-straining testing frame, fitted with a $250 \mathrm{kN}$ dynamic-static actuator powered by a hydraulic pump and connected to a digital feedback controller. The latter controlled the load level, the magnitude of displacement at failure and other functions related to the test performance (e.g. load

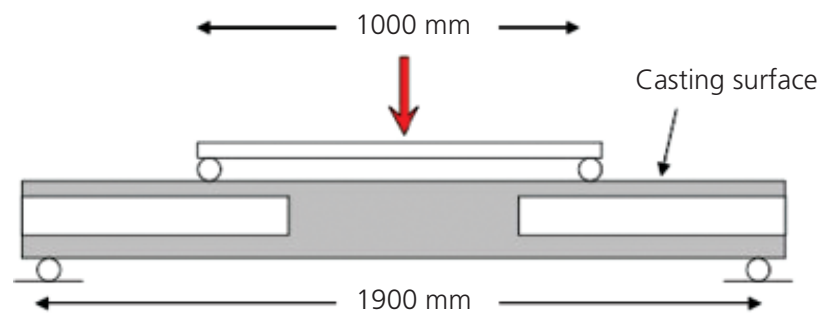

(a)

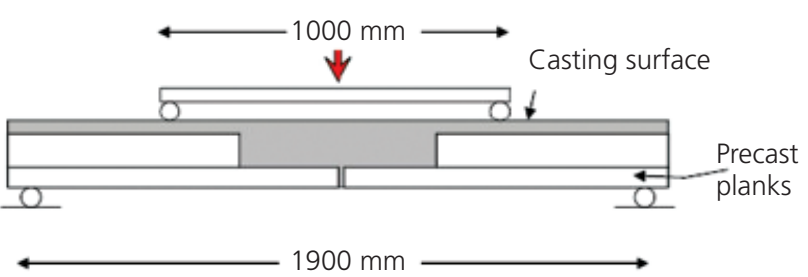

(b)

Figure 7. Test set-up for (a) monolithic specimen in positive bending and (b) composite specimen in positive bending

\begin{tabular}{llll}
\hline Specimen & Type & Bending & Comments \\
\hline 1 & Control & Positive & Monolithic specimen - no precast elements \\
2 & Control & Negative & As specimen 1 \\
3 & Composite & Positive & Composite specimen utilising precast elements with lattice girders \\
4 & Composite & Negative & As specimen 3 \\
5 & Composite & Positive & Composite specimen utilising precast elements without lattice girders \\
6 & Composite & Positive & As specimen 3 but with shorter $(600$ mm long) lap bars \\
7 & Composite & Negative & As specimen 6
\end{tabular}

Table 1. Test specimens 
reversal). The test set-up is very stiff and therefore only small deformations of its own could occur. For the control tests, two measurements were recorded for each specimen (tests 1 and 2): the load from the load cell of the testing machine and the vertical deflection at the centre point. In the case of the composite specimens, (tests 3 to 7) the strains from six strain gauges (20 $\mathrm{mm}$ gauge length) attached to the three reinforcing bars across the gap in the planks were also recorded. The vertical deflection was measured by a pair of linear variable differential transformers (LVDTs) placed under the specimen on either side of the centreline across the width of the specimen.

The testing procedure for all specimens started at zero load and zero displacement. The load was gradually increased until a crack initiated, thus obtaining the cracking load $\boldsymbol{P}_{\text {cr. }}$. Following initial cracking, the specimens were unloaded to $10 \mathrm{kN}$ and immediately after loaded again to a load $20 \%$ higher than the cracking load. Subsequently, in order to obtain the unloading curve for postcracking, the specimens were again unloaded to $10 \mathrm{kN}$. Finally the specimens were re-loaded to the maximum displacement possible with the testing frame. The yield load $\boldsymbol{P}_{\mathrm{y}}$, load at $25 \mathrm{~mm}$ displacement $\boldsymbol{P}_{25}$ and the load at maximum displacement $\boldsymbol{P}_{\max }$ were recorded.

\section{Test results}

\subsection{Measured material properties}

The materials' properties are required in order to perform accurate predictions of the joint behaviour according the codes. Hence, the material strengths were determined by testing and the results are listed in Tables 2 and 3. Note that concrete strength

\begin{tabular}{lcc}
\hline Specimen & \multicolumn{2}{c}{ Concrete cube strength $f_{\text {cu }}: \mathrm{MPa}$} \\
\cline { 2 - 3 } & In situ & Precast elements \\
\hline 1 & $32 \cdot 17$ & - \\
2 & $33 \cdot 42$ & - \\
3 & $32 \cdot 17$ & 54.46 \\
4 & $33 \cdot 42$ & $53 \cdot 81$ \\
5,6 & 30.67 & 67.44 \\
7 & 31.45 & 72.02
\end{tabular}

Table 2. Measured in situ and precast concrete strengths

\begin{tabular}{lcc}
\hline $\begin{array}{l}\text { Rebar } \\
\text { size }\end{array}$ & $\begin{array}{c}\text { Yield strength, } f_{\text {sy }}: \\
\mathrm{N} / \mathrm{mm}^{2}\end{array}$ & $\begin{array}{c}\text { Ultimate strength } f_{\text {su }}: \\
\mathrm{N} / \mathrm{mm}^{2}\end{array}$ \\
\hline T10 & $530 \cdot 3$ & $718 \cdot 2$ \\
Table 3. Measured reinforcement strengths & \\
\hline
\end{tabular}

tests were conducted on $100 \mathrm{~mm} \times 100 \mathrm{~mm} \times 100 \mathrm{~mm}$ cubes. As far as in situ concrete is concerned, tests were performed on the 28 th day of curing. The cubes corresponding to the precast elements have been cast 3 months prior to the testing day.

\subsection{Monolithic specimen 1 - positive bending}

Figure 8 shows the load against mid-span deflection (average of the two LVDT readings) of monolithic specimen 1 in positive bending, highlighting the salient load levels, whereas Figure 9 shows how the cracks developed during the loading. Note that the specimen failed suddenly at a deflection of $51 \mathrm{~mm}$ due to the rupture of the bottom continuous reinforcement mesh. The three $2 \mathrm{~m}$ long reinforcing bars forming this mesh sustained significant necking, which resulted in a 'cup and cone' fracture of the bars at mid-span (Figure 9(d)).

\subsection{Monolithic specimen 2 - negative bending}

In order to simulate negative bending, the beam was turned upside down so that the casting surface then formed the tension side of the specimen. Figure 10 shows the load-deflection response of this specimen and Figure 11 shows the development of cracks during loading and the specimen at failure. As can be observed, the specimen sustained a load of $226 \mathrm{kN}$ at failure. Although the specimen had suffered multiple flexural cracking, failure occurred due to a large shear crack from one of the supports (Figure 11(b)).

\subsection{Composite specimen 3 - positive bending}

Figure 12 shows the load-deflection response of composite specimen 3 in positive bending and Figure 13 shows the crack propagation during the last stages of the test. The specimen failed due to a large crack that initiated at the root of the $10 \mathrm{~mm}$ gap between the planks.

\subsection{Composite specimen 4 - negative bending}

The requirements for the negative bending test of composite specimen 4 are the same as described earlier for the negative bending test of monolithic specimen 2. Figure 14 illustrates the load-deflection response of the specimen, whereas Figure 15

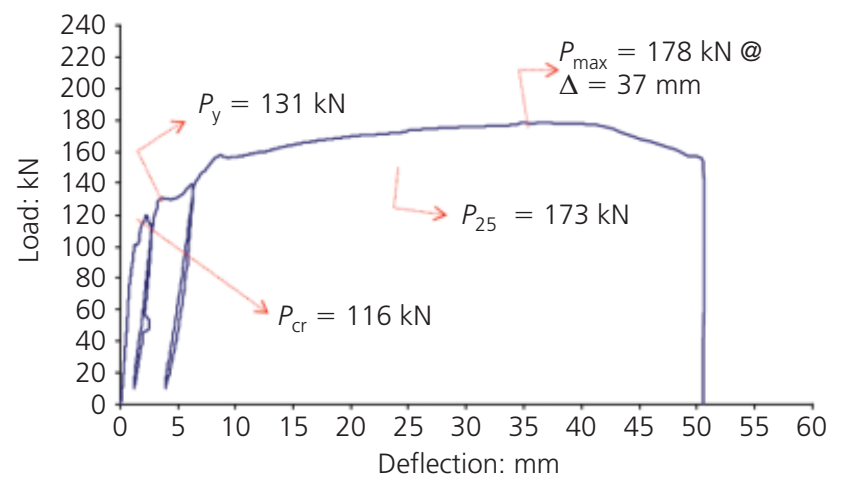

Figure 8. Load-deflection response of monolithic specimen 1 in positive bending 


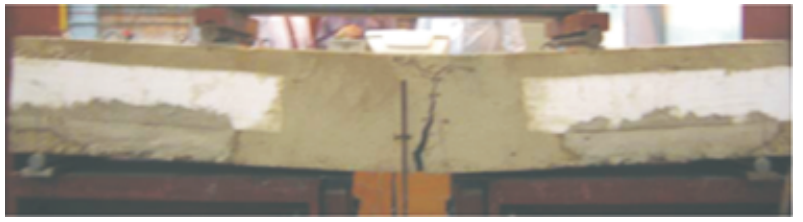

(a)

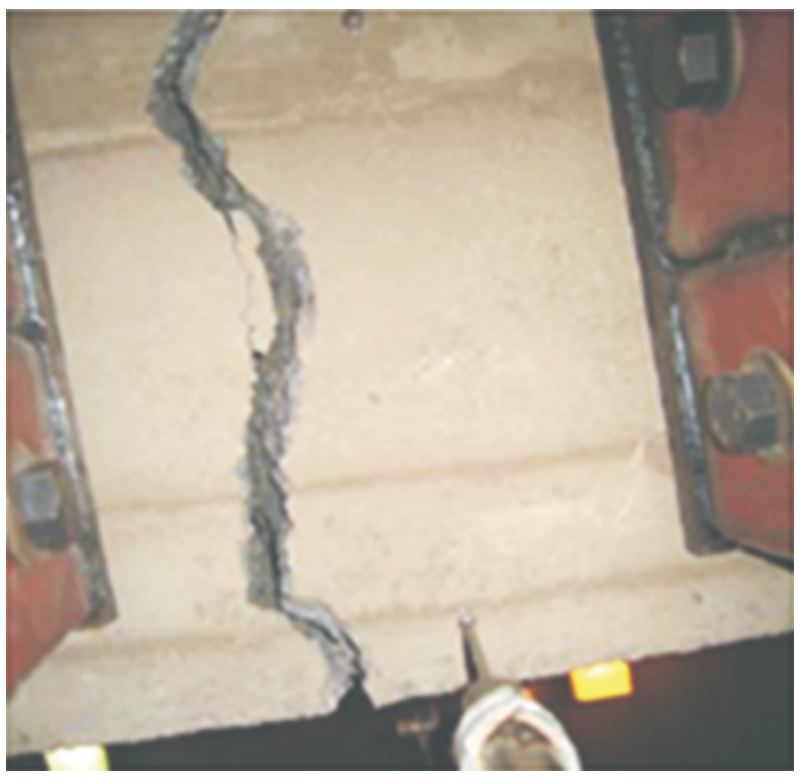

(c)

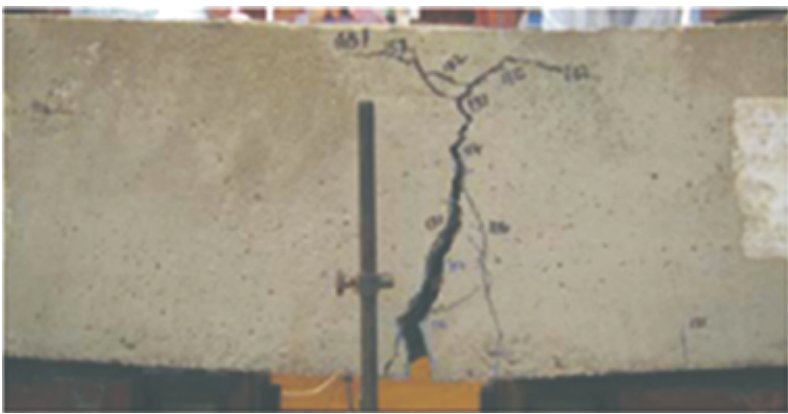

(b)

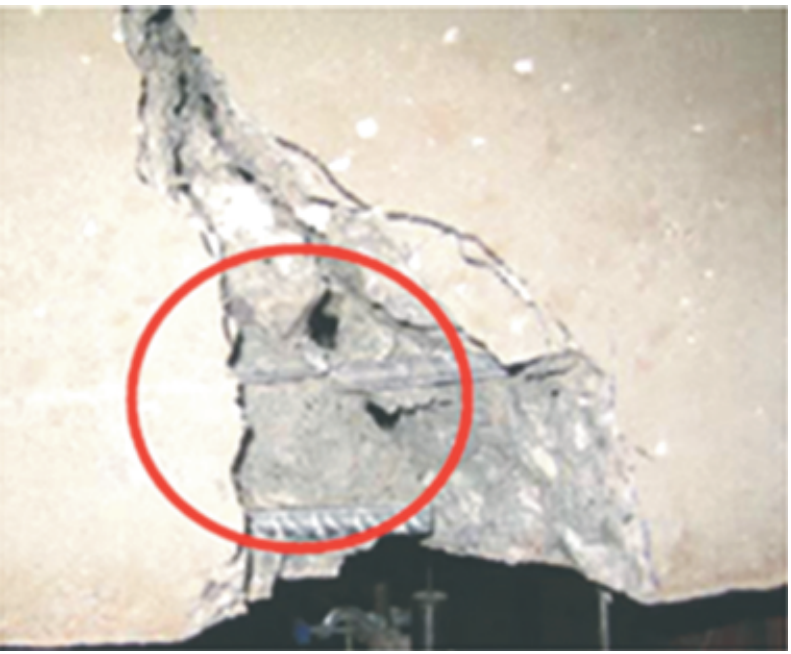

(d)

Figure 9. (a) Specimen 1 at failure. (b) Detail of crack opening at failure. (c) Crack path viewed from the underside of specimen. (d) 'Cup and cone' fracture of the three bottom continuous reinforcing bars

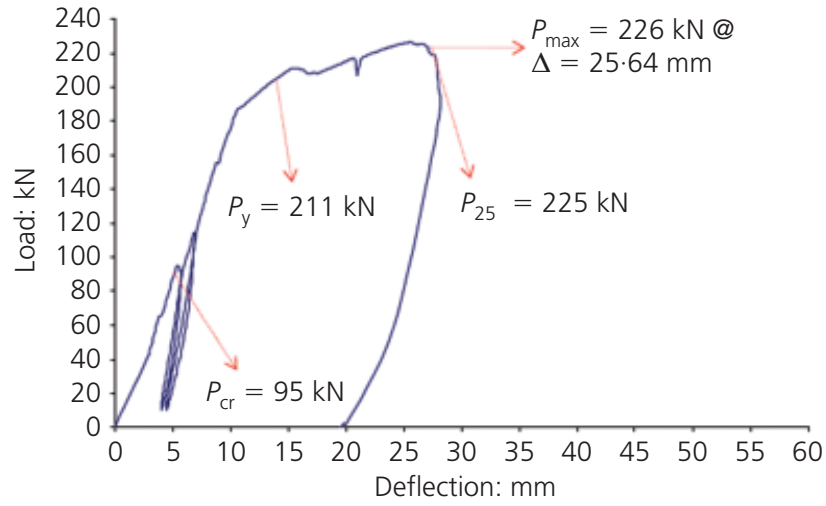

Figure 10. Load-deflection response of monolithic specimen 2 in negative bending

shows the specimen during the loading process. This specimen failed in flexure with three flexural cracks in the loaded span of the topping concrete all converging towards the gap between the planks. Note that at the maximum load, the $10 \mathrm{~mm}$ gap between the planks on the compression side was nearly closed.

\subsection{Composite specimen 5 - positive bending}

Figure 16 shows the load-deflection response of composite specimen 5 in positive bending. The initial behaviour of the specimen was as expected but, because of the absence of the lateral lattice girder, one of the precast planks delaminated from the topping concrete resulting in an abrupt failure of the specimen (Figure 17). It should be mentioned that when the load exceeded $100 \mathrm{kN}$, acoustic emission was audible as a result of the initiation of the debonding between the precast and in situ concrete phases. The absence of lateral lattice girders resulted in a significant reduction in the anchorage between the precast and the in situ concrete.

\subsection{Composite specimen 6 - positive bending}

Figure 18 shows the load-deflection response of composite specimen 6 in positive bending. The specimen failed in flexure and its response was very similar to that of composite specimen 3 
Performance of joints in RC slabs for two-

way spanning action

Stehle, Kanellopoulos and Karihaloo

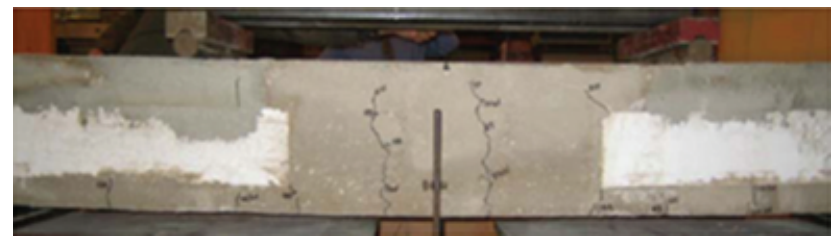

(a)

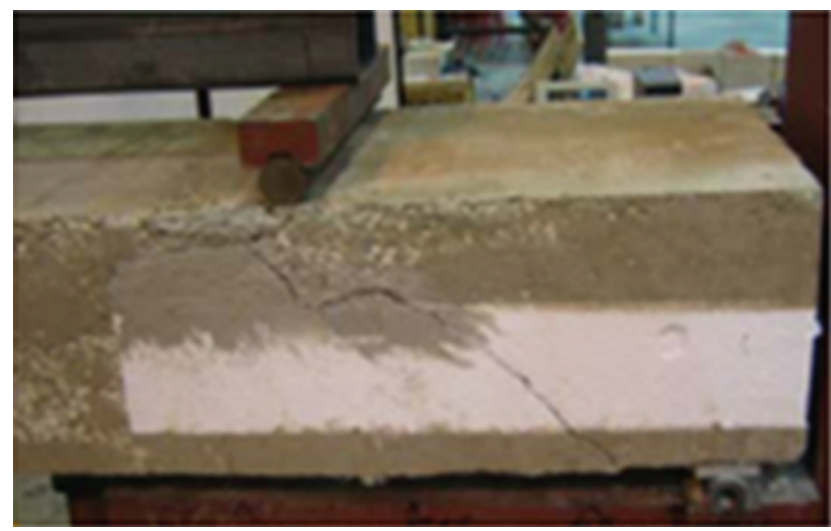

(b)

Figure 11. Specimen 2: (a) multiple cracking; (b) shear crack at failure

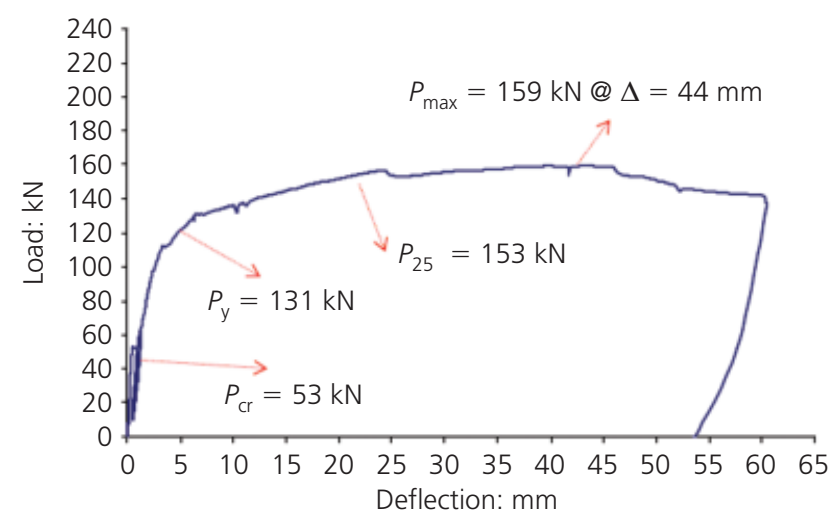

Figure 12. Load-deflection response of composite specimen 3 in positive bending

(Figure 12). No delamination at all was observed in this specimen (Figure 19). As mentioned, the specimen responded roughly in the same manner as composite specimen 3. Although the maximum loads in both specimens were nearly the same $(159 \mathrm{kN}$ in specimen 3 and $154 \mathrm{kN}$ in specimen 6), the corresponding displacements were very different. In specimen 3 the maximum load of $159 \mathrm{kN}$ was reached at a displacement of $44 \mathrm{~mm}$, whereas in specimen 6 it was reached at a deflection of only $26 \mathrm{~mm}$. This is evidently a result of the reduction in length of the three lap bars (from $1000 \mathrm{~mm}$ in specimen 3 to $600 \mathrm{~mm}$ in specimen 6) resting across the $10 \mathrm{~mm}$ gap in the two planks, as this was the only substantial difference between the specimens.

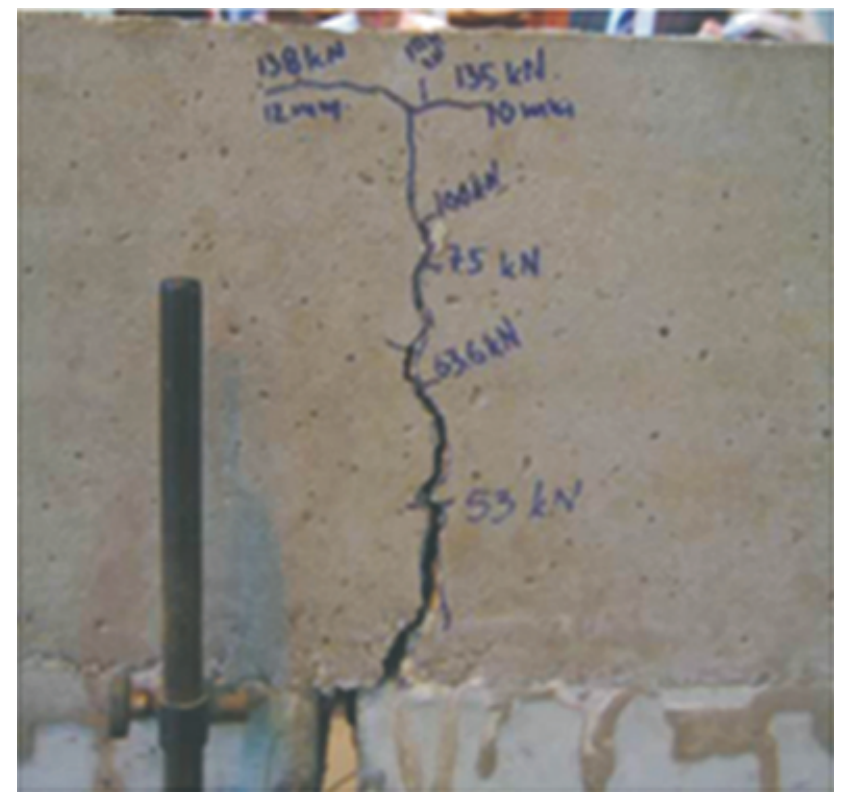

(a)

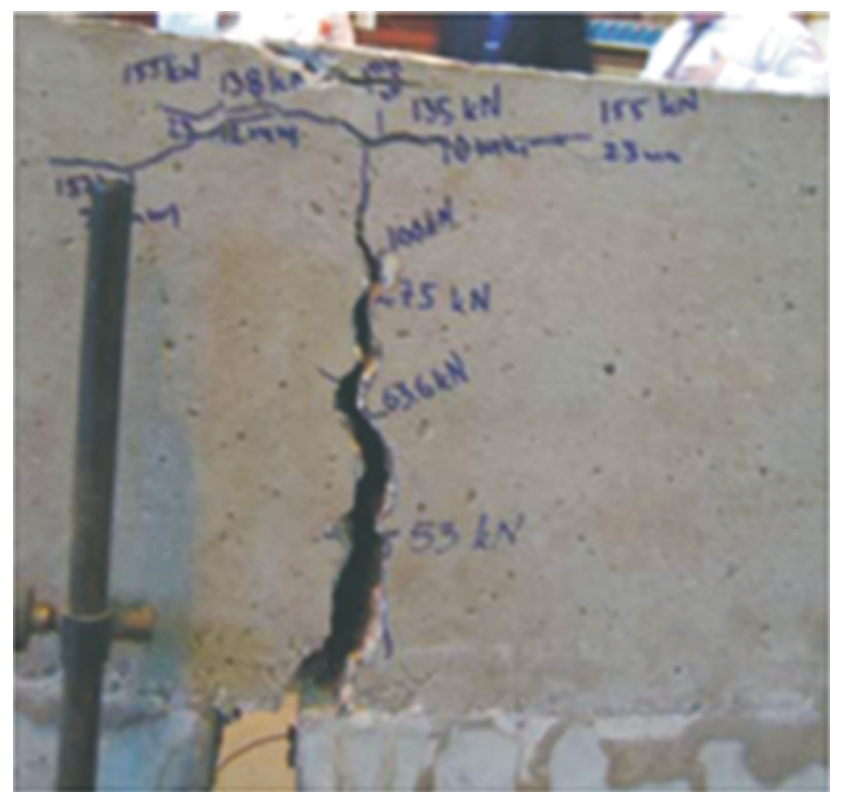

(b)

Figure 13. Specimen 3: (a) crack opening as load is increased; (b) specimen close to ultimate load

\subsection{Composite specimen 7 - negative bending}

Figure 20 shows the load-deflection curve for composite specimen 7. The failure pattern of this specimen showed some similarities with the failure pattern of monolithic specimen 2 (Figure 10). Although the specimen suffered multiple cracking, failure occurred due to a shear crack from one of the supports once the maximum load had been reached. However, the specimen did not fail abruptly because of additional tensile reinforcement (Figure 21). At failure, the shear crack had 


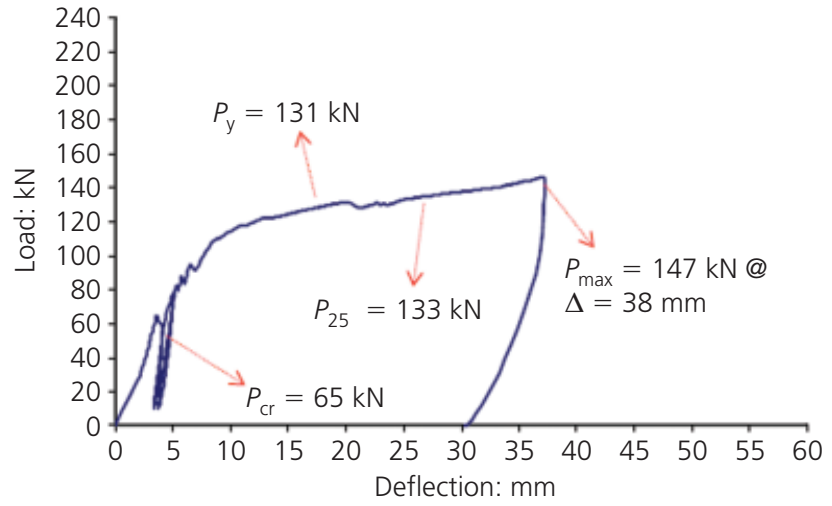

Figure 14. Load-deflection response of composite specimen 4 in negative bending

propagated through the entire width of the specimen (Figure 22).

\section{Discussion of test results}

The attained cracking, yield and maximum strengths of the test specimens are listed and compared in Tables 4, 5 and 6. Table 4 shows that the design yield and cracking moments were all achieved, except in specimen 5 where poor anchorage conditions for the 'lap' bars were provided. The presence of lattice girders and their close vicinity to the 'lap' bars are shown to be important factors for achieving satisfactory joint performance.

Ideally, the joint should perform as well as a monolithic specimen. Table 5 indicates that the cracking moment in positive bending is significantly less than for the monolithic specimen (specimen 1) for all the composite specimens. This is not unexpected since the gross depth of the concrete is less than for the monolithic specimen because the in situ topping of the composite specimens did not flow into the $10 \mathrm{~mm}$ gap between the precast planks. The main implication for the reduced cracking strength is that, overall, the slab will be less stiff when considering serviceability deflections. However, since the extent of the reduced stiffness is small (only at the $10 \mathrm{~mm}$ gap), the overall effect on deflection is not considered to be greatly significant, but should still be allowed for in design.

In terms of strength design, the ultimate moment is the factor that should be considered. Table 5 shows that specimens 3 and 6 achieved full yield strength as did the monolithic specimen 1 ; this can be attributed to the better bond conditions for the 'lap' bars than for specimen 5. A $500 \mathrm{~mm}$ lap length appears to be sufficient, even though a design lap length of $528 \mathrm{~mm}$ was established (Section 2.3). The performance beyond yield is not quite as good for specimens 3 and 6 as compared with specimen 1. However, the strength is only approximately $10 \%$ less. Such a strength reduction in post-yield behaviour is not of concern since there is clearly a great deal of ductile performance present. The

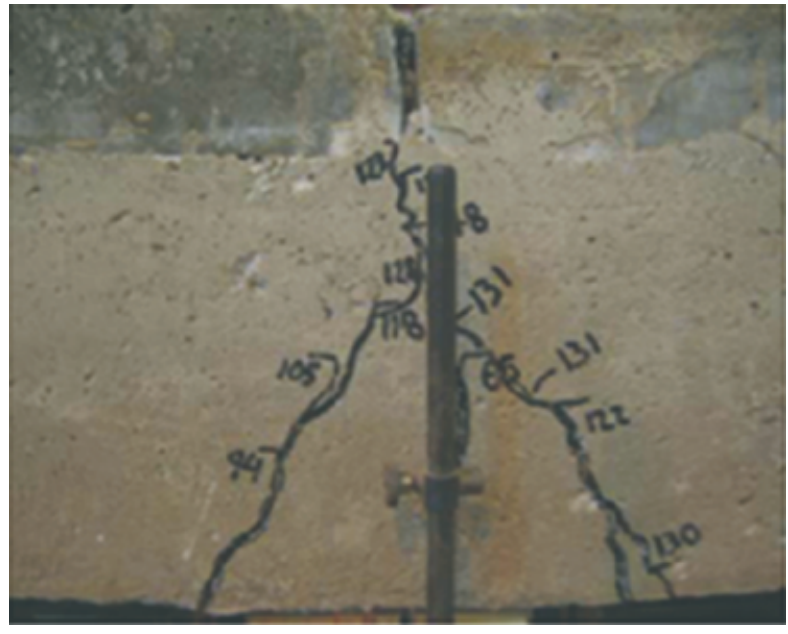

(a)

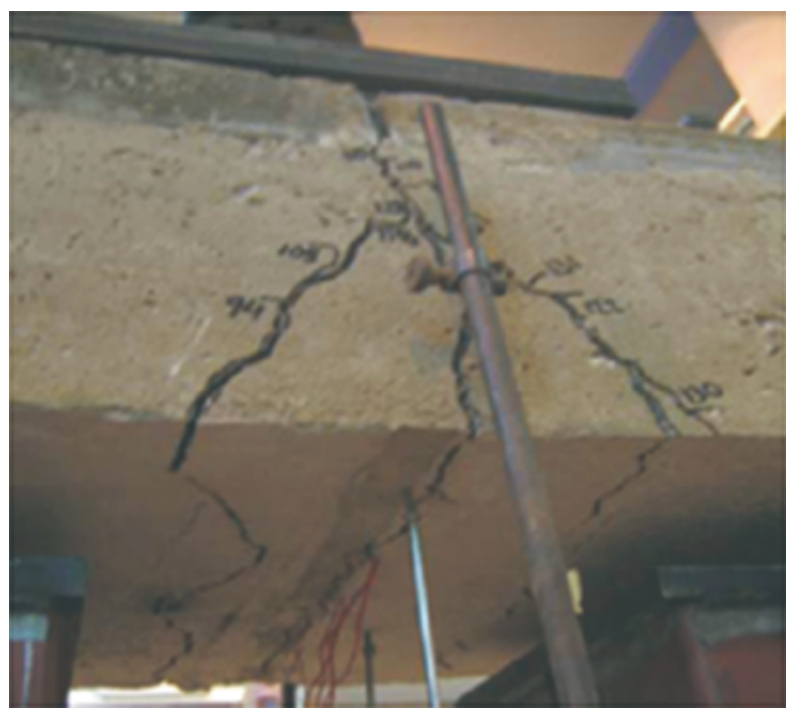

(b)

Figure 15. Specimen 4 close to deflection of $25 \mathrm{~mm}$. (b) 'Wedge' formed by cracks converging towards the gap in the planks at failure

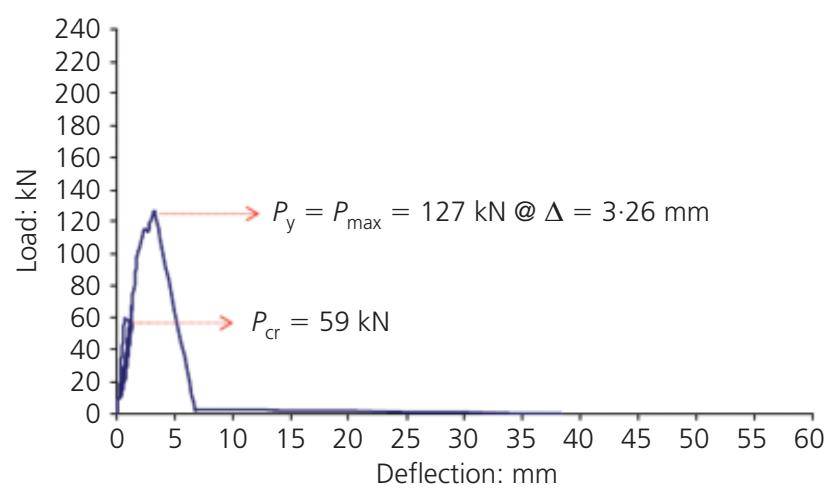

Figure 16. Load-deflection response of composite specimen 5 in positive bending 


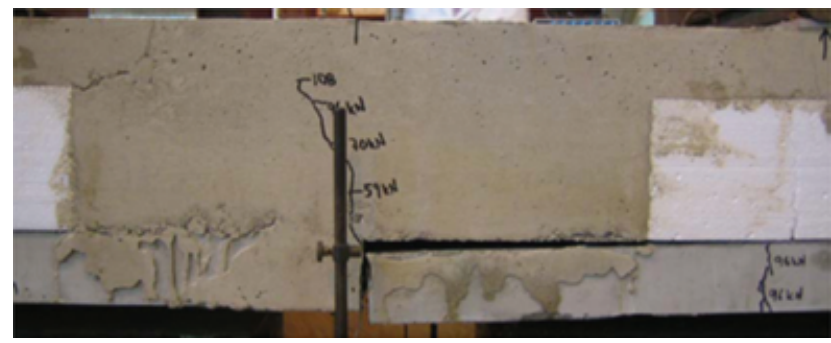

Figure 17. Detail of the delamination between the two concrete phases in specimen 5

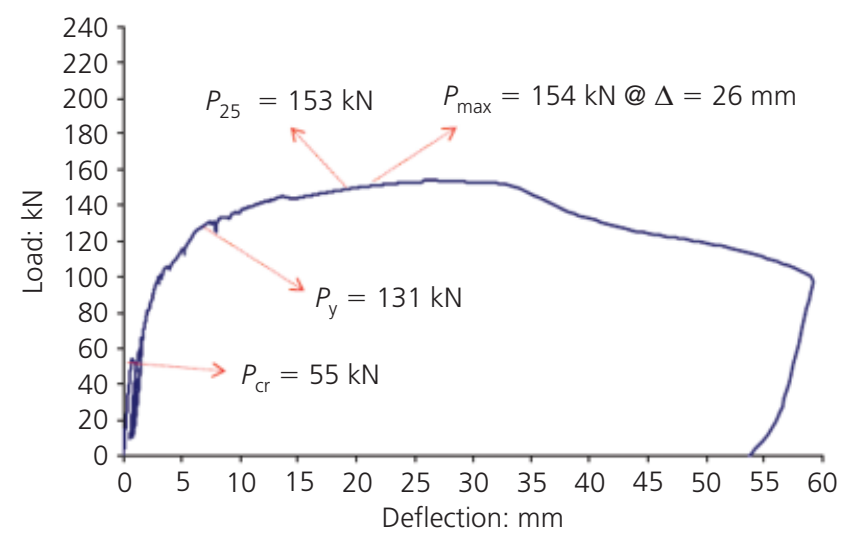

Figure 18. Load-deflection response of composite specimen 6 in positive bending

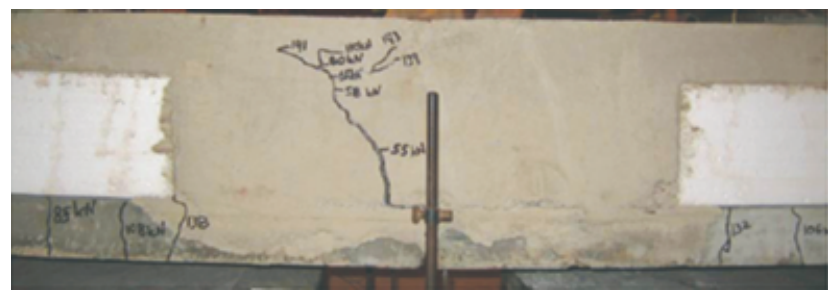

(a)

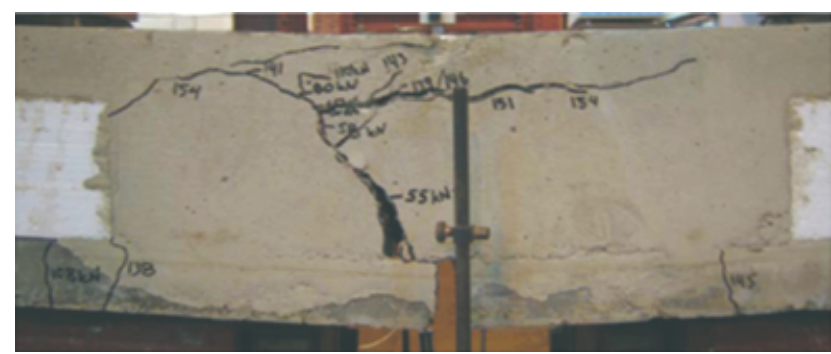

(b)

Figure 19. Crack propagation in specimen 6 with increasing load: (a) cracking beyond yield load; (b) crack pattern at failure
Performance of joints in RC slabs for two-

way spanning action

Stehle, Kanellopoulos and Karihaloo

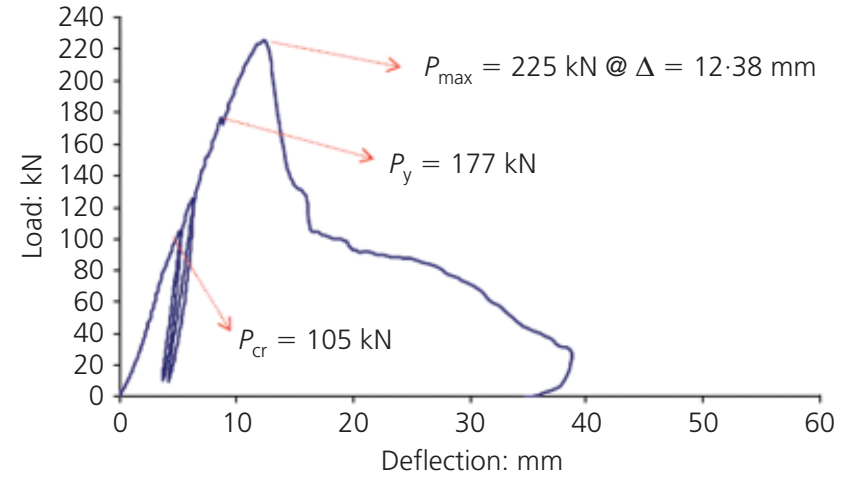

Figure 20. Load-deflection response of composite specimen 7 in negative bending

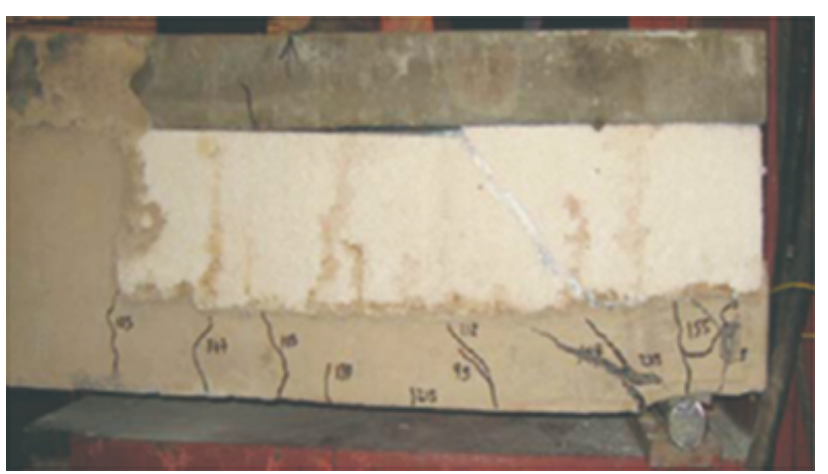

(a)

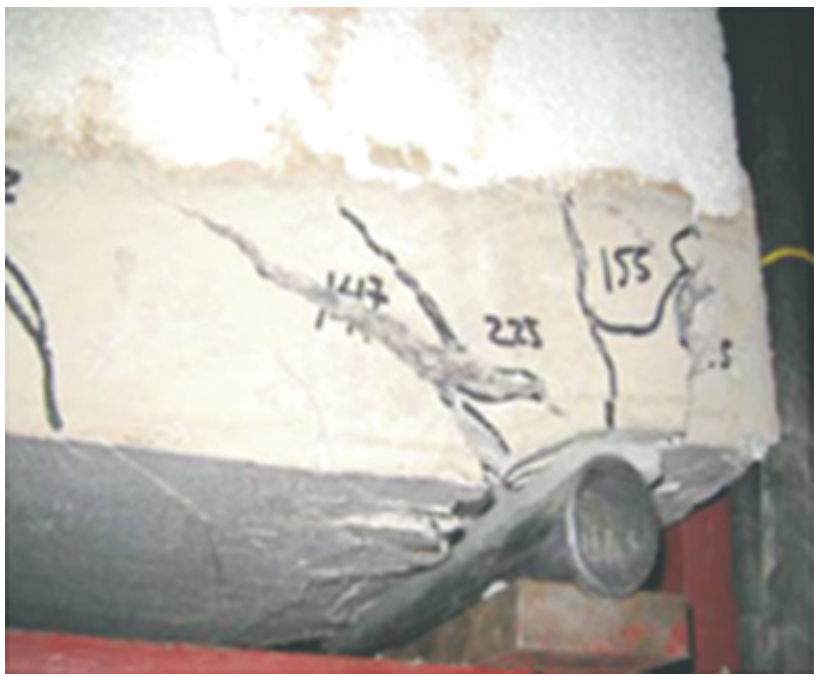

(b)

Figure 21. Crack development at various loading levels in specimen 7: (a) multiple cracking on the side where the failure occurred (note the shear crack); (b) detail of the support after yielding of the specimen 


\begin{tabular}{|c|c|c|c|c|c|c|c|}
\hline \multicolumn{2}{|c|}{ Test } & \multirow{2}{*}{$\begin{array}{c}\text { Design } \\
\text { moment: } \\
\text { kNm* } \\
20 \cdot 0\end{array}$} & \multirow{2}{*}{$\begin{array}{l}\text { Predicted } \\
\text { moment: } \\
\text { kNm }\end{array}$} & \multirow{2}{*}{$\begin{array}{c}\begin{array}{c}\text { Applied } \\
\text { load: } \\
\text { kN }\end{array} \\
116\end{array}$} & \multirow{2}{*}{$\begin{array}{c}\text { Measured } \\
\text { moment: } \\
\text { kNmt }\end{array}$} & \multirow{2}{*}{$\begin{array}{c}\text { Ratio of measured to } \\
\text { predicted moment: } \\
\%\end{array}$} & \multirow{2}{*}{$\begin{array}{c}\text { Ratio of measured to } \\
\text { design moment: } \\
\%\end{array}$} \\
\hline 1 & Cracking, $M_{\mathrm{cr}}$ & & & & & & \\
\hline & Yield, $M_{y}$ & $24 \cdot 6$ & $26 \cdot 19$ & 131 & $29 \cdot 5^{* *}$ & 113 & 120 \\
\hline & Maximum, $M_{\max }$ & NAt† & $35 \cdot 4 \neq \neq$ & 178 & $40 \cdot 1 \S \S$ & 113 & NA \\
\hline \multirow[t]{3}{*}{2} & Cracking, $M_{\mathrm{cr}}$ & $20 \cdot 0$ & $19 \cdot 5$ & 95 & 21.4 & 110 & 107 \\
\hline & Yield, $M_{y}$ & $30 \cdot 8$ & $32 \cdot 6$ & 211 & $47 \cdot 5$ & 145 & 154 \\
\hline & Maximum, $M_{\max }$ & NA & $44 \cdot 2$ & 226 & $50 \cdot 9$ & 115 & NA \\
\hline \multirow[t]{3}{*}{3} & Cracking, $M_{\mathrm{cr}}$ & $11 \cdot 2$ & $10 \cdot 8$ & 53 & $11 \cdot 9$ & 111 & 106 \\
\hline & Yield, $M_{\mathrm{y}}$ & $24 \cdot 6$ & $26 \cdot 1$ & 131 & $29 \cdot 5$ & 113 & 120 \\
\hline & Maximum, $M_{\max }$ & NA & $35 \cdot 4$ & 159 & $35 \cdot 8$ & 101 & NA \\
\hline \multirow[t]{3}{*}{4} & Cracking, $M_{\mathrm{cr}}$ & $11 \cdot 2$ & $11 \cdot 0$ & 65 & 14.6 & 133 & 130 \\
\hline & Yield, $M_{\mathrm{y}}$ & $24 \cdot 6$ & $26 \cdot 1$ & 131 & $29 \cdot 5$ & 113 & 120 \\
\hline & Maximum, $M_{\max }$ & NA & $35 \cdot 4$ & 147 & $33 \cdot 1$ & 94 & NA \\
\hline \multirow[t]{3}{*}{5} & Cracking, $M_{\mathrm{cr}}$ & $11 \cdot 2$ & $10 \cdot 5$ & 59 & $13 \cdot 3$ & 126 & 118 \\
\hline & Yield, $M_{y}$ & $41 \cdot 0$ & $43 \cdot 5$ & 127 & $28 \cdot 6$ & 66 & 70 \\
\hline & Maximum, $M_{\max }$ & NA & $58 \cdot 9$ & 127 & $28 \cdot 6$ & 48 & NA \\
\hline \multirow[t]{3}{*}{6} & Cracking, $M_{\mathrm{cr}}$ & $11 \cdot 2$ & $10 \cdot 5$ & 55 & $12 \cdot 4$ & 118 & 110 \\
\hline & Yield, $M_{\mathrm{y}}$ & $24 \cdot 6$ & $26 \cdot 1$ & 131 & $29 \cdot 5$ & 113 & 120 \\
\hline & Maximum, $M_{\max }$ & NA & $35 \cdot 4$ & 154 & $34 \cdot 7$ & 98 & NA \\
\hline \multirow[t]{3}{*}{7} & Cracking, $M_{\mathrm{cr}}$ & $11 \cdot 2$ & $10 \cdot 6$ & 105 & $23 \cdot 6$ & 222 & 210 \\
\hline & Yield, $M_{y}$ & $37 \cdot 3$ & $39 \cdot 6$ & 177 & $39 \cdot 8$ & 101 & 107 \\
\hline & Maximum, $M_{\max }$ & NA & $53 \cdot 6$ & 225 & $50 \cdot 6$ & 94 & NA \\
\hline
\end{tabular}

* Design moments based on nominal design material properties

$\dagger$ Measured moment $=$ applied load $\times 0.45 / 2$

$\neq$ Predicted cracking moment $=M_{\mathrm{cr}}=f_{\mathrm{ct}} b D^{2} / 6$

$\S$ Measured cracking moment defined as where a sudden drop in the load-displacement curve occurred

ๆ Predicted yield moment calculated based on the mean measured yield strength of the reinforcement, $f_{5 y} . M_{y}=0.95 A_{s} f_{s y} d$ (approximately)

** Measured yield moment defined as where the load-displacement curve begins to flatten out

†† Maximum moment beyond yield is not normally calculated for design

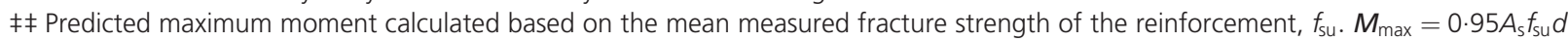
(approximately)

$\S \S$ Measured maximum moment defined at the maximum load on the load-displacement curve

Table 4. Measured results versus predicted and design values

\begin{tabular}{lcccccccc} 
Specimen no. & $P_{\mathrm{cr}}: \mathrm{kN}$ & $P_{\mathrm{cr}} / P_{\mathrm{cr}, \text { test } 1: \%}$ & $P_{\mathrm{y}}: \mathrm{kN}$ & $P_{\mathrm{y}} / P_{\mathrm{y}, \text { test 1 }: \%}$ & $P_{25}: \mathrm{kN}$ & $P_{25} / P_{25, \text { test 1 }}: \%$ & $P_{\max }: \mathrm{kN}$ & $P_{\max } / P_{\max , \text { test } 1: \%}$ \\
\hline 1 & 116 & 100 & 131 & 100 & 173 & 100 & 178 & 100 \\
3 & 53 & 46 & 131 & 100 & 153 & 88 & 159 & 89 \\
5 & 59 & 51 & 127 & 97 & $\mathrm{NA}$ & $\mathrm{NA}$ & 127 & 71 \\
6 & 55 & 47 & 131 & 100 & 154 & 89 & 154 & 87
\end{tabular}

Table 5. Measured results for positive bending tests compared with monolithic specimen 1 results

reduction in strength, however, may be attributable to bond slip occurring in the post-yield range.

The results for the negative bending of the composite specimens vary considerably, as shown in Table 6. For specimen 4, a concrete mix with low slump was used and so did not fill the gap between the planks. Thus the overall and effective depths of the section should be based on an overall depth of $225 \mathrm{~mm}$, which is considerably less than the $300 \mathrm{~mm}$ available for the monolithic specimen. Specimen 7, however, was constructed using a con- 


\begin{tabular}{lcccccccc}
\hline Specimen no. & $P_{\mathrm{cr}}: \mathrm{kN}$ & $P_{\mathrm{cr}} / P_{\mathrm{cr}, \text { test 2 }}: \%$ & $P_{\mathrm{y}}: \mathrm{kN}$ & $P_{\mathrm{y}} / P_{\mathrm{y}, \text { test 2 }}: \%$ & $P_{25}: \mathrm{kN}$ & $P_{25} / P_{25, \text { test 2 }}: \%$ & $P_{\max }: \mathrm{kN}$ & $P_{\max } / P_{\max , \text { test 2 }}: \%$ \\
\hline 2 & 95 & 100 & 211 & 100 & 225 & 100 & 226 & 100 \\
4 & 65 & 68 & 131 & 62 & 133 & 59 & 147 & 65 \\
7 & 105 & 111 & 177 & 84 & $\mathrm{NA}$ & $\mathrm{NA}$ & 225 & 100
\end{tabular}

Table 6. Measured results for positive bending tests compared with monolithic specimen 2 results

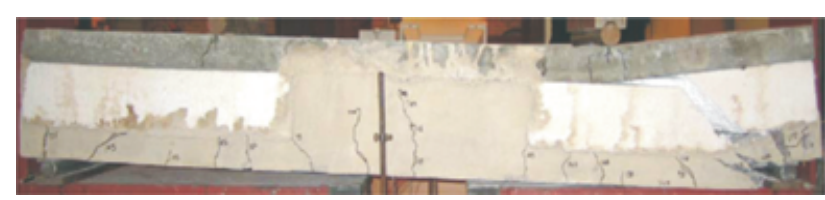

(a)

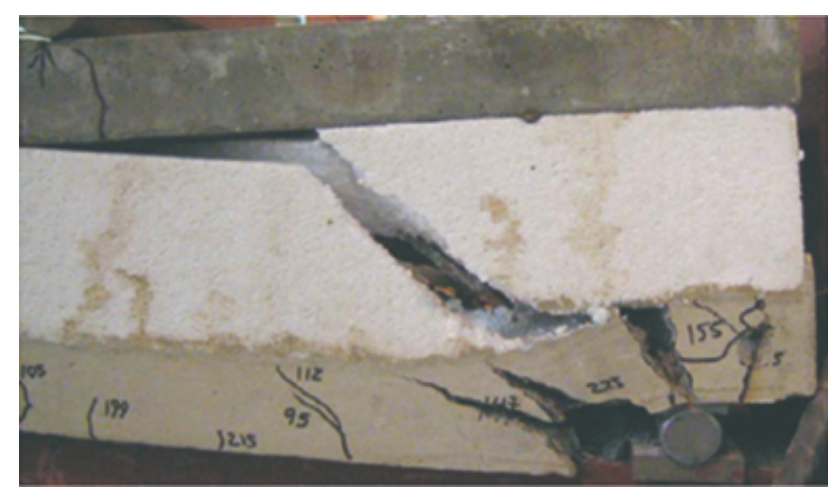

(b)

Figure 22. Specimen 7 at complete fracture: (a) specimen at failure; (b) detail of the large shear crack that initiated the failure (note that the section completely fractured through the entire width)

crete mix with a higher slump, which was observed to fill the $10 \mathrm{~mm}$ gap between the precast planks, and thus a greater section depth was effective in terms of negative moment strength calculations. This adjustment was not made in the estimated design and predicted strengths in Table 5 since it was thought that it would be difficult in practice to rely on the gap filling with concrete.

\section{Conclusions}

It is clear from the experimental results that, if adequate bond conditions are provided, joints in filigree slabs can satisfactorily transfer bending forces and achieve two-way spanning action. The test results indicate that the following conditions provide adequate bond performance.

(a) Adequate bar anchorage length. For a T10 bar, a $500 \mathrm{~mm}$ anchorage length appears to be satisfactory even if the precast interface is not deliberately roughened and even if the bar is placed directly on the plank (i.e. the in situ concrete topping cannot flow around the bar).

(b) Provision of sufficient lattice girders within the vicinity of the 'lap' bars to ensure horizontal shear is transferred from the in situ portion to the precast portion of the composite slab. For a T10 bar, two T7 diagonal webs of a lattice girder located within approximately $50 \mathrm{~mm}$ of the T10 bar appear to be sufficient.

\section{Recommendations}

Taking into account the results presented here, the design of twoway spanning slabs may be detailed. Caution should be exercised if the design parameters deviate far beyond those considered here. In these cases, further testing is recommended to verify the design approach. Further work of a more generic nature could be undertaken to optimise and understand the importance of all the design parameters more fully. In particular, the parameters that might be varied include

(a) concrete grade

(b) concrete consistency

(c) aggregate size

(d) effect of roughening the precast interface

(e) diameter of 'lap' bars

$(f)$ anchorage length of 'lap' bars

( $g$ ) diameter of diagonal bars in the lattice girders

(h) position of lattice girder diagonal bars relative to 'lap' bars

(i) overall depth of slab

(j) thickness of the precast plank

(k) depth of the 'lap' bar (i.e. placed directly on plank or slightly above)

( $l$ ) ratio of vertical shear to moment (this test series considered zero shear and constant moment in the 'lap' bar region).

\section{Acknowledgements}

Laing O'Rourke plc provided the detailed drawings of the test specimens as well as the precast filigree planks, and sponsored the testing. The test specimens were made and tested in the Structural Performance Laboratory at Cardiff University. The staff of the laboratory also deserve our special thanks.

\section{REFERENCES}

ACl (American Concrete Institute) (2008) ACI 318: Building Code Requirements for Structural Concrete. ACI, Farmington Hills, MI. 
BSI (British Standards Institution) (2004) BS EN 1992: Eurocode 2: Design of concrete structures. Part 1-1: General rules and rules for buildings. BSI, Milton Keynes.

BubbleDeck (2010) http://www.bubbledeck.com/ (accessed 16/02/ 2010).

Cheng YM (1995) Nonlinear optimal design model of concrete reinforcement truss plank. Journal of Structural Optimisation 9(3-4): 250-253.
Cobiax Technology (2010) http://www.cobiax.ch/ (accessed 16/ 02/2010).

HCP (Hanson Concrete Products) (2010) http:// www.omnidec.co.uk/ (accessed 16/02/2010).

Kanellopoulos A, Stehle J and Karihaloo BL (2007) The Performance of Joints in Filigree Slabs to Achieve 2-way Spanning Action. Cardiff University and Laing O'Rourke plc, Internal technical report, pp. 1-54.

\section{WHAT DO YOU THINK?}

To discuss this paper, please email up to 500 words to the editor at journals@ice.org.uk. Your contribution will be forwarded to the author(s) for a reply and, if considered appropriate by the editorial panel, will be published as a discussion in a future issue of the journal.

Proceedings journals rely entirely on contributions sent in by civil engineering professionals, academics and students. Papers should be $2000-5000$ words long (briefing papers should be 1000-2000 words long), with adequate illustrations and references. You can submit your paper online via www.icevirtuallibrary.com/content/journals, where you will also find detailed author guidelines. 